\title{
EPIDEMIOLOGICAL SIGNIFICANCE OF THE COLONIZATION OF STREPTOCOCCUS AGALACTIAE IN THE ANORECTUM AND ENDOCERVIX OF NON-PARTURIENTS IN JOS, NIGERIA
}

\author{
DS NSAGHA ${ }^{1,2^{*}}$, HLF Kamga $^{3}$, JCN Assob $^{4}$, AL Njunda $^{3}$, CSS BELLO, $^{2}$ YT KANDAKAI-OLUKEMI ${ }^{2}$
}

${ }^{1}$ Department of Public Health and Hygiene, Faculty of Health Sciences, University of Buea, Buea, Cameroon; ${ }^{2}$ Department of Medical Microbiology, Faculty of Health Sciences, University of Jos, Jos, Nigeria; ${ }^{3}$ Department of Medical Laboratory Sciences, Faculty of Health Sciences, University of Buea, Buea, Cameroon; ${ }^{4}$ Department of Biomedical Sciences, Faculty of Health Sciences, University of Buea, Buea, Cameroon.

* Correspondence: Dr. Dickson S. Nsagha, Department of Public Health and Hygiene, Medicine Programme, Faculty of Health Sciences, University of Buea, PO Box 63, Buea, Cameroon. Tel: (237) 77499429 E-mail: dsnsagha@gmail.com or nsaghads@hotmail.com

\section{ABSTRACT}

Knowledge of Group B Streptococcus (GBS) carriage and infections in Africa is very scanty but few cases have been reported in Nigeria in particular. Streptococcus agalactiae has been reported to cause infections and diseases in non-parturients and adults ranging from bacteremia, osteomylitis, arthritis, and endocarditis to breast abscess among others, hence the necessity for this study. Fifty six non-pregnant women of different age groups and social status were screened for GBS in Plateau State Specialist Hospital using the Christie, Atkins and MunchPetersen (CAMP) and hippurate hydrolysis tests. Two (3.6\%) of the 56 women were positive for GBS. The 2 isolates were all from the anorectum. The endocervix yielded no culture. The antibiogram showed that ampicillin is the drug of choice with all isolates (100\%) sensitive to the drug. No statistically significant relationship was observed between the clinical and epidemiological characteristics of the patients and GBS carriage $(\mathbf{P}>\mathbf{0 . 0 5})$. This survey shows a much lower carriage proportion than that reported in Ibadan, Nigeria from non-parturients.

Key words: Streptococcus agalactiae, epidemiology, anorectum, endocervix, non-parturients

\section{INTRODUCTION}

Streptococcus agalactiae (Lancefield Group B) originally known to cause bovine mastitis (1) is now a recognized pathogen in the neonatal period and an important cause of puerperal sepsis $(2,3,4)$. Only recently, however, has the importance of this organism as a cause of infections in adults been recognized $(5,6)$. In Europe, USA and Australia, this organism has been causing serious havoc to the dairy industry and is occasionally a health hazard especially in the neonatal period and in adults $(6,7,8,9)$. Few cases of GBS infections and carriage have been reported in Nigeria $(2,8,10,11,12$, 14) in particular. The intestinal tract appears to be the primary reservoir and likely source of vaginal colonization in pregnant women $(10,11,14,15)$. This relationship makes the genital and lower intestinal tracts known habitats of the organism.

The importance of early detection of asymptomatic people in the community through screening in order to reduce morbidity and mortality from communicable diseases is a vital part of public health (11). We report here the investigation of the epidemiological significance of colonization of Lancefield Group B streptococcus of the anorectum and endocervix among non-parturients in a health institution in Nigeria.

\section{MATERIALS AND METHODS}

Fifty six out-patient-non-pregnant women attending the Plateau State Specialist Hospital, Jos, Nigeria, for various health reasons were screened for GBS carriage. The subjects' consent was sought and gained and volunteers were asked to fill a questionnaire which contained information on age, religion, marital status, history of vaginal discharge, recent antibiotic use, miscarriage, family planning, educational and occupational status. Volunteers who could not read or write nor understand English were communicated to, through an interpreter in Hausa (Hausa is the local common language of the study area). The ethical clearance for the study was obtained from the Jos University Teaching Hospital.
Fifty-six anorectal and 56 endocervical swabs (112 swabs in all) were collected through a sterile speculum from each patient using sterile swab sticks and touch light by nurses. Specimens were immediately transferred to the Medical Microbiology Laboratory of the Jos University Teaching

Hospital for laboratory investigation. Cultures were made on $5 \%$ Neomycin sheep blood agar plates incubated at $37^{\circ} \mathrm{C}$ in a candle jar overnight and subsequently sub-cultured to new blood agar plates and incubated as stated above. No transport medium was used since the two hospitals are not far apart. The investigation was carried out using standard microbiological techniques (microscopy, culture, colonial morphology, Gram staining and catalase tests). The isolates were presumptively identified using the CAMP (16) and hippurate hydrolysis (17) tests.

GBS cultures were streaked on blood agar plates and the diskdiffusion method used to carry out the antibiogram with multiple commercial disks (Antee Diagnostic, UK). The plates were incubated overnight at $37^{\circ} \mathrm{C}$ in a candle jar after which the plates were read for zones of inhibition.

It was assumed that anorectal colonization would be greater than that of the endocervix and that GBS carriage was not going to vary with the clinical and epidemiological characteristics of the patients. Statistical analysis was carried out using SPSS (Statistical Package for Social Sciences) with the chi-square and Fisher exact tests at $95 \%$ confidence.

\section{RESULTS}

Out of 56 non-pregnant women, 2(3.6\%) were positive for GBS. A colonization proportion was discovered per site as follows: endocervix [0(0.0\%)] and anorectum [3(3.6\%)] (Table 1). One of the GBS isolates was identified using the 144 CAMP test and the other with the hippurate hydrolysis reaction. The characteristic of the subjects were divided into two groups: the epidemiological and clinical characteristics. Table 2 shows the epidemiological characteristics and GBS 
carriage, and Table 3 shows the clinical characteristic and the colonization of GBS. There was a positive correlation between the demographic characteristics but none was statistically significant $(\mathrm{P}=0.06)$. Table 4 shows the results of the antibiogram of the common drugs used in Jos for the two isolates. The number of sensitive and resistant Streptococcus agalactiae was statistically significant $(\mathrm{P}<0.05)$. It was not possible to investigate whether any of the patients was down with any streptococcal group B diseases. It was not also possible to send the GBS isolates for typing in a reference laboratory because of insufficient laboratory preservation facilities.

TABLE 1: GBS CULTURE STATUS ACCORDING TO SITE AMONG NON-PREGNANT WOMEN IN JOS

\begin{tabular}{|c|c|c|c|c|}
\hline Site & $\begin{array}{l}\text { No of Swabs } \\
\text { Collected }\end{array}$ & $\begin{array}{l}\text { GBS Positive } \\
\text { No (\%) }\end{array}$ & $\begin{array}{l}\text { GBS Negative } \\
\text { No }(\%)\end{array}$ & P-Value \\
\hline Endocervix & 56 & $0(0.0)$ & $56(100)$ & \\
\hline Anorectum & 56 & $2(3.6)$ & $54(96.4)$ & \\
\hline
\end{tabular}

TABLE 2: GBS CARRIAGE PROPORTIONS AND THE EPIDEMIOLOGICAL CHARACTERISTICS IN NON-PREGNANT WOMEN $(\mathrm{n}=\mathbf{5 6})$

\begin{tabular}{lcc}
\hline Epidemiological characteristics & No. tested & $\begin{array}{c}\text { GBS positive } \\
\text { No (\%) }\end{array}$ \\
\hline $\begin{array}{l}\text { Education } \\
\text { Literate }\end{array}$ & 50 & $2(100)$ \\
Illiterate & 06 & $0(00)$ \\
Occupation & & \\
Employed & 51 & $1(50)$ \\
Unemployed & 05 & $1(50)$ \\
Religion & & \\
Christian & 30 & $2(100)$ \\
Muslim & 26 & $0(00)$ \\
Others & 00 & $0(00)$ \\
Marital status & & \\
Monogamy & & $1(50)$ \\
Polygamy & 28 & $0(00)$ \\
Single & 05 & $1(50)$ \\
Others (separated, divorced, \\
widowed)
\end{tabular}

TABLE 3: GBS CARRIAGE AND THE CLINICAL CHARACTERISTICS IN NON-PREGNANT WOMEN (n=56)

\begin{tabular}{|c|c|c|c|}
\hline Clinical Characteristics & No. tested & GBS positive & No $(\%)$ \\
\hline \multicolumn{4}{|l|}{ Age range (years) } \\
\hline$<19$ & 08 & & $0(000)$ \\
\hline 20-25 & 12 & & $0(000)$ \\
\hline 26-31 & 27 & & $2(100)$ \\
\hline $32-36$ & 06 & & $0(000)$ \\
\hline$>\mathbf{3 7}$ & 03 & & $0(000)$ \\
\hline \multicolumn{4}{|l|}{ Vaginal discharge } \\
\hline Yes & 11 & & $0(000)$ \\
\hline No & 45 & & $2(100)$ \\
\hline \multicolumn{4}{|c|}{ Recent antibiotic treatment (weeks) } \\
\hline None & 07 & & $\mathbf{0}(00)$ \\
\hline 1 & 25 & & 1(50) \\
\hline 2 & 17 & & 1(50) \\
\hline$>2$ & 07 & & $0(00)$ \\
\hline \multicolumn{4}{|l|}{ Miscarriage } \\
\hline Yes & 11 & & $0(00)$ \\
\hline No & 45 & & $2(100)$ \\
\hline \multicolumn{4}{|l|}{ Family planning } \\
\hline Practised & 21 & 145 & $0(00)$ \\
\hline Not practised & 35 & & $2(100)$ \\
\hline
\end{tabular}


TABLE 4: SENSITIVITY PATTERN OF GBS ISOLATED IN THE JOS ENVIRONMENT

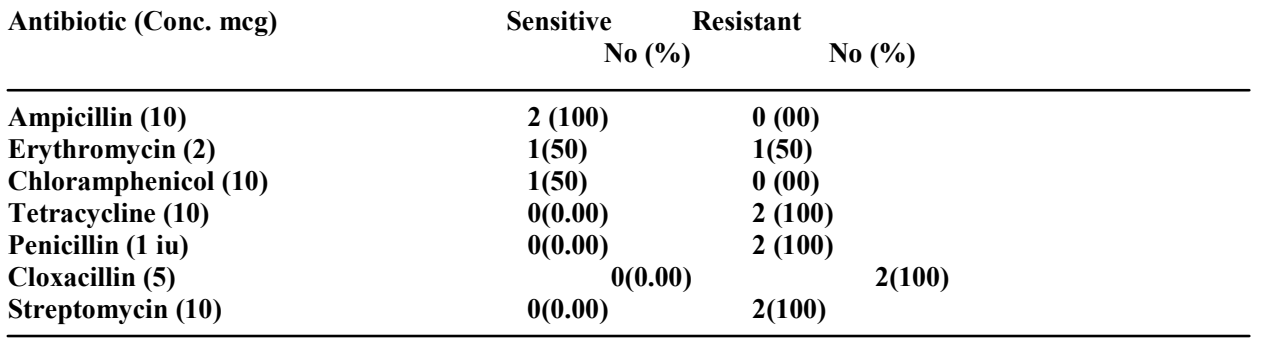

\section{DISCUSSION}

The testing of asymptomatic people in society can help to control communicable diseases morbidity and mortality. Knowledge of GBS infections and diseases in Africa is scanty because of sparsely equipped bacteriology laboratories which results in the organism being missed in the course of diagnosis. Most GBS cases isolated in Nigeria were from pregnant women $(8,10,11,13,14)$ and infants $(8,18)$. The isolation of Streptococcus agalactiae in the anorectum of non-parturients in this environment should instill awareness in the minds of health officials to review their health control policies towards this organism.

Streptococcus agalactiae was isolated from women attending venereology clinics (19\%) in Ibadan, Nigeria (8). A 3.6\% colonization proportion in non-parturients in Jos is much lower compared to that observed by Onile (13) in Ibadan, Nigeria, among non-pregnant women. Many reasons affecting sample collection, treatment, site and methods of identification and perhaps environmental factors as well as variations in maternal colonization from place to place have been postulated $(8,10,11,13,14)$ to support this difference. The anorectal colonization of $3.6 \%$ and an endocervical colonization of $0.00 \%$ in this study agree with a discrepancy of anorectal and endocervical colonization in pregnancy earlier reported in this region (10). It has been postulated that anorectal carriage could be due to migration of GBS from the naso-pharyngeal flora to the anorectum $(2,10,20,21)$ since GBS is a normal flora in the nasopharynx.

The carriage proportion of $3.6 \%$ in non-parturients is lower than that reported in parturients in this area (10) and other regions in Nigeria $(8,14)$. The absence of GBS in the endocervix of non-parturients could be due to the lack of ecological conditions, high acidic milieu and a glycogen rich mucosa that prevail in the pregnant cervix (22).

No relationship was established between GBS carriage and the social status of the subjects even though it was higher for literates and did not vary for employment. GBS carriage did not vary according to religion or marital status. Marital status was introduced because polygamy is very common in this area for both Muslims and Christians since the organism is sexually transmitted. The epidemiological character on religion was suggested because it was envisaged that the Muslim cultural habit of washing the 'dirty parts' (genital and peri-anal regions) before ablution (i.e. "tsarki" in Hausa) could have an effect on GBS carriage. The findings of the epidemiological characteristics and GBS carriage were not statistically significant $(\mathrm{P}>0.05)$.
In accordance with an earlier report in this area on pregnant women $(8,9)$, these isolates were concentrated in the agegroup 26-31. This could be due to some underlying disease or deficiency (nutritional, hormonal, metabolic or immunological) $(7,23)$. No relationship was established between vaginal discharge and miscarriage in our study $(\mathrm{P}>$ 0.05). The two isolates were all from women who did not practice any form of family planning. The effect of contraceptives altering the normal female genital flora has been implicated in increased GBS infections (4). Contraceptives can disrupt the normal vaginal flora, hence the $0.00 \%$ observed in women who had practiced any form of family planning (condoms, oral contraceptives, intrauterine contraceptive devices and injections).

Patients who had been on antibiotics for one or two weeks previously still harboured GBS. This could be explained by the fact that these may have been resistant strains. All the two GBS isolates in the Jos environment were sensitive to ampicillin. Ampicillin is safe and can be used for the prophylactic control of GBS infections and diseases in Nigeria. Resistant GBS was statistically significant with respect to the sensitive ones $(\mathrm{P}<0.05)$. The high resistance to other antibiotics may be due to antibiotic abuse as Onile (24) had reported on high antibiotic abuse in Nigeria.

In conclusion, further studies on the carriage and acquisition of group B streptococcus in adults is necessary to obtain more information on the reservoirs and sources of the organism. More work is still required to be done on the association between carrier state and disease and control studies. Ampicillin is the drug of choice for the treatment of GBS diseases in Nigeria.

\section{CONTRIBUTION OF AUTHORS}

DSN conceived and designed the study; collected and analyzed the data; prepared the draft and final write up; HLFK, JCNA and ALN participated in drafting the manuscript and substantially revised the manuscript; CSSB designed and supervised the study, and substantially revised the manuscript; YTKO supervised the work and revised the manuscript. All authors read and approved the manuscript.

\section{ACKNOWLEDGEMENTS}

We appreciate the permission of Dr. E.A. Akabe, former sole Administrator of Plateau State Specialist Hospital to use his patients in the study. The technical assistance of Mr. D.U. Idiong of the Medical Microbiology Department, Jos University Teaching Hospital is acknowledged. This work is part of an M.Sc thesis that was successfully defended by the lead author at the University of Jos, Nigeria. 


\section{REFERENCES}

1. Ayers, S.H. and Nudge C.S. The streptococci of the bovine udder. J Infect Dis 1922; 31: 40-50.

2. Onile, B.A. Group B streptococcal neonatal and infant infections in Nigeria. A review and update. East Afric Med J 1984; 61(8): 591-595.

3. Siegel, J.D and McCracken G.H.J. Sepsis neonatorum. NEJM 1981; 304: 642-664.

4. Wilson, H.D and Chenwald, E. Sepsis neonatorum, Pediat Clin North A 1974; 21:571-582.

5. Small, C.B., Slater L.N., Slvati E.A., et al. Group B streptococcal Arthritis in adults. A J Med 1984; 76(367): 577-578.

6. Weiss, R.L. and Matsen J.M. Group B Streptococcal Breast Abscess. Archive Path Lab Med 1987; 111:7475 .

7. Bayer; A.S., Chow A.W., Anthony, B.F. and Gruze, L.B. Serious infections in adults due to group B streptococci-clinical and serotypic characterization. A J Med 1976; 61:498-503.

8. Onile, B.A. Group B streptococcal carriage in Nigeria. Trans $R$ Soc Trop Med Hyg 1980; 74:367-370.

9. Parker, M.T. Neonatal streptococcal infections. Postgrad Med J 1977; 53: 598-608.

10. Nsagha, D.S., Bello, C.S.S., Kandakai-Olukemi, Y.T. Hippurate Hydrolysis and Christie Atkins, Munch - Petersen Tests as epidemiological diagnostic tools for Streptococcus agalactiae carriage in pregnancy. East Afri Med J 2000; 77(1): 32-34.

11. Nsagha, D.S., Bello, C.S.S., Kandakai-Olukemi, Y.T. Maternal carriage in pregnancy of group B streptococcus in Jos: Relation of endocervical and anorectal colonization. Nig $Q J$ Hosp Med 1997; 7(1): 53-56.

13. Onile, B.A. Group B streptococcal infections in Ibadan. MD Thesis 1983, University of Ibadan, Ibadan, Nigeria.
14. Uhiara, J.E. Group B streptococcal carriage among parturients and their neonates in Zaria, Nigerian. Afri J Med Medical Sci 1998; 22:79-83.

15. Onile, B.A. Review of group B streptococci and their infections. Afri J Med Medical Sci 1985; 14:131143.

16. Christie, R; Atkins, N.E; Munch-Peterson E. A note on a lytic phenomenon shown by group B streptococci. Aust J Exp Biology Med Sci 1944; 22: $197-200$

17. Hwang, M. and Ederer G.M. Hippurate hydrolysis method for presumptive identification of group B streptococci. J Clin Microb 1975; 1: 114-115.

18. Odugbemi, T.O., Ajasin, M.A and Awodiji J. Streptococcus group B meningitis: A case report. East Afri Med J 1979; 56(8): 399-401.

19. Christensen, K., Ripta, T., Agrup, C. and Christenson, P. Group B streptococci in human urethral and cervical specimens. Scand J Infect Dis 1976; 8: $75-76$.

20. Christensen, K.K., Christensen, P., Flamhole, L. and Ripta, T. Frequencies of streptococci of groups $\mathrm{A}, \mathrm{B}, \mathrm{C}, \mathrm{D}$ and $\mathrm{G}$ in urethra and cervical swab specimens from patients with suspected gonococcal infection. Acta Path Microbiol Scand 1974; 82: 470-474.

21. Franciosis, A. A., Knostman, J.D., and Zimmermann, R.A. Group B streptococcal neonatal and infant infections. J Pediat 1973; 82: 707-718.

22. Reid, T.M.S. Emergence of group B streptococci in obstetrics and perianal infections. BMJ 1975; 2: 233-235.

23. Ross, P.W., Easmon, C.S.F., Colman, G., Bagg, T., Cumming, C.G., Hostings, M.J.G. Group B streptococcus: Profile of an organism-occasional review. J Med Microbiol 1984; 18(2): 139-166.

24. Onile, B.A. (1992). Abuse of chemotherapeutic agents. Nig Med Pract 1992; 23 (56): 90-91. 